\title{
Aliphatic Aldehydes Produced by Heating Chinese Cooking
}

\author{
J.-M. Lin, S.-J. Liou \\ Institute of Environmental Health, College of Public Health, National Taiwan \\ University, Room 1451, Number 1, Jen Ai Road, 1st Sec., Taipei, Taiwan 100, \\ Republic of China
}

Received: 25 November 1999/Accepted: 10 March 2000

The Chinese style of cuisine requires steaming, boiling, or using oil to pan fry or deep fry. If the cuisine is prepared by stir-fry, the cooking oil in the fry pan is ordinarily heated in advance to approximately $300^{\circ} \mathrm{C}$. A variety of chemical reactions occur while the temperature of the cooking oil in the pan is being elevated and the cooking materials are finally loaded into the hot pan. Chemicals in fumes generated from pan fry cooking are thought to be associated with contents of cooking oil and foods. Indoor exposure to the fume has been associated with respiratory diseases as an important risk particularly for women and cookers in Taiwan and other areas where pan-fry cooking is popular (Ko et al, 1997; Law and Day, 1976; Schoenberg et al, 1984; Coggon et al, 1984; Coggon and Wield, 1993). Several studies have identified carcinogens in the fume, including benzo[a]pyrene, dibenz[a,h]anthracene, benzene and formaldehyde (Li et al, 1994; Shields et al, 1995). Bioassay has also demonstrated that the condensate of the fume from cooking oils and foods is genotoxic and mutagenic (Berg et al, 1988; Berg et al, 1990; Felton et al, 1986).

This study was to quantitate volatile aliphatic aldehydes produced in the fume-including formaldehyde, acetaldehyde, acrolein and propionaldehyde--while soybean oil, peanut oil and homemade pork lard were being heated at selected temperatures resemble to pan frying conditions.

\section{METHODS AND MATERIALS}

The homemade lard was extracted by heating the subcutaneous fat of pork and filtered using greaseless cotton while it was being cooled to room temperature. Peanut oils and soybean oil were purchased from a certified food manufacturer in Taiwan with a purity of $99.9 \%$ and containing no additive antioxidant. Each oil sample $(340 \pm 9 \mathrm{mg})$ was measured into an iron planchette (diameter $3 \mathrm{~cm}$ ) with a fringe (high $1.5 \mathrm{~cm}$ ) at room temperature, and then heated at a selected and controlled temperature. The levels of temperature selected for tests were $150 \pm 2$ ${ }^{\circ} \mathrm{C}, 200 \pm 2{ }^{\circ} \mathrm{C}, 250 \pm 2{ }^{\circ} \mathrm{C}, 300 \pm 2{ }^{\circ} \mathrm{C}, 350 \pm 2{ }^{\circ} \mathrm{C}$ and $400 \pm 2{ }^{\circ} \mathrm{C}$. The sample should not be charred when heated for 30 minutes at $150^{\circ} \mathrm{C}, 200^{\circ} \mathrm{C}, 250^{\circ} \mathrm{C}$ or 300 ${ }^{\circ} \mathrm{C}$, for 5.5 minutes at $350^{\circ} \mathrm{C}$ and for 3 minutes at $400^{\circ} \mathrm{C}$. Each pyrolysis test for 


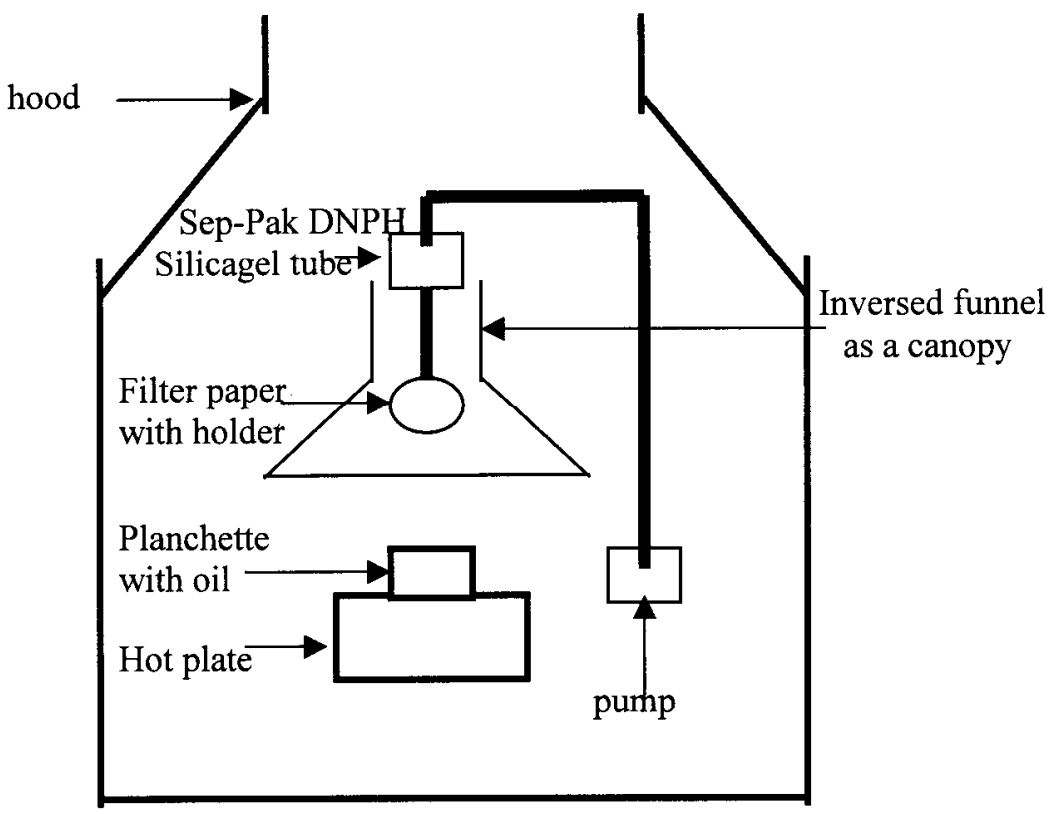

Figure 1. Schematic diagram for generation and collection of cooking oil fume

each oil sample was performed in triplicate at each selected temperature. The fume was collected using glass fiber filters ( $37 \mathrm{~mm}, 225-7 \mathrm{SKC}$, USA) incorporated with the Sep-Pak DNPH-silica cartridges (37500, Millipore, USA) at a flow rate of $1.6 \mathrm{~L} / \mathrm{min}$. The Sep-Pak DNPH-silica cartridge contained $0.35 \mathrm{~g}$ silica gel coated with $1.0 \mathrm{mg}$ 2,4-dinitrophenyl hydrazine (2,4-DNPH). The sampling probe was located at a distance of $30 \mathrm{~cm}$ away from the iron planchette. All the setup for fume generation and sample collection was placed inside a specially designed hood $(155 \times 67 \times 120 \mathrm{~cm})$, as shown in the schematic diagram in Figure 1.

The filter paper was weighed before and after sampling, and was subsequently extracted with $5 \mathrm{~mL}$ acetonitrile containing $0.125 \mathrm{mg}$ 2,4-DNPH (GR,3081, Merck, Germany), then filtered with a syringe filter (PTFE, $13 \mathrm{~mm}, 0.45 \mu \mathrm{m}$, Gelman , USA). The Sep-Pak cartridge was eluted with $5 \mathrm{~mL}$ acetonitrile at a flow rate of $3 \mathrm{~mL} / \mathrm{min}$. After spiking with $10 \mu \mathrm{L}$ internal standard $(0.1 \mathrm{mg} / \mathrm{mL}$ of p-terphenyl, Fluka, Switzerland) in $1 \mathrm{~mL}$ sample of extract or eluate, the sample was analyzed using a high performance liquid chromatograph (HPLC) (PU-980, Jasco, Japan) equipped with an absorbance detector (UV/VIS Detector, UV 975, Jasco, Japan) operating initially at $254 \mathrm{~nm}$ for 11 minutes and then at $277 \mathrm{~nm}$. The reverse phase column (Enviro Sep-PP, 125x $3.20 \mathrm{~mm}$, Phenomenex, USA) was applied to the mobile phase of acetonitrile/deionized water. The programming solvent gradient was conducted at a flow rate of $1 \mathrm{~mL} / \mathrm{min}$. The initial composition of acetonitrile was $40 \%$, which increased linearly to $83 \%$ within 20 minutes, and then decreased to $40 \%$ in the succeeding 10 minutes. 
The HPLC chromatograms of aliphatic aldehyde were obtained and recorded in a computerized data processing system (Shung Hwa Co., Taiwan). The retention time for formaldehyde, acetaldehyde, acrolein and propionaldehyde relative to that of p-terphenyl was calculated, respectively. Upon the relative retention time, each aldehyde was identified.

Standard materials of formaldehyde, acetaldehyde and propionaldehyde were purchased from Merck, Germany. Acrolein (100\% TK151) was purchased from the THETA Corp, Germany. Each was utilized to prepare a series of standard solution with the concentration ranged from $0.1 \mu \mathrm{g} / \mathrm{mL}$ to $2.0 \mu \mathrm{g} / \mathrm{mL}$. The calibration curve for each aldehyde was plotted by the corresponding area ratio versus the concentration ratio of aldehyde standard to internal standard. The limits of detection were $11 \mathrm{ng} / \mathrm{mL}, 24 \mathrm{ng} / \mathrm{mL}, 20 \mathrm{ng} / \mathrm{mL}$ and $13 \mathrm{ng} / \mathrm{mL}$ respectively for formaldehyde, acetaldehyde, acrolein and propionaldehyde.

\section{RESULTS AND DISCUSSION}

Figure 2 shows that the particulate mass increased with the elevation of temperature when the cooking oils were heated between $150^{\circ} \mathrm{C}$ and $400^{\circ} \mathrm{C}$. However, HPLC chromatograrn showed no particulate-bound aldehyde in the acetonitrile extracts of filter-collected samples. In fact, the recoveries of DNPH derivatives of particulate-bound aldehydes were unknown although a satisfactory recovery (averaged $114 \pm 6 \%$ ) was obtained as the authentic DNPH derivatives of aldehydes were spiked on the plain filter and extracted by acetonitrile. Under this condition, we suppose that aliphatic aldehydes occurred only in gas phase. The chromatogram in Figure 3 shows peaks for DNPH derivatives of formaldehyde, acetaldehyde, acrolein and propionaldehyde and several unidentified components. The unidentified peaks were likely DNPH derivatives of other aldehydes and ketones due to a Schiff reaction.

The aldehydes are formed in a various species and concentrations in the pyrolysis , depending on the kind of cooking oil heated and the temperature applied to the oil. Table 1 lists the average yields of formaldehyde, acetaldehyde, acrolein and propionaldehyde by temperature and oil applied. The average yield of total aliphatic aldehydes was less than $0.5 \mathrm{ppm} / \mathrm{mg}$-min for most tests if the heating temperature was $300^{\circ} \mathrm{C}$ or less, regardless of the type of cooking oil. An exception, due to higher yield of acrolein, was $1.5 \mathrm{ppm} / \mathrm{mg}$-min of total aldehyde measured for the fume of soybean oil or the lard at $150^{\circ} \mathrm{C}$. This implies that parts of material in the oil were pyrolyzed earlier even at a lower temperature. The pyrolysis process was slower until higher temperature reached.

Table 1 also shows elevated yields of aliphatic aldehydes were noticeable when the temperature raised to $350^{\circ} \mathrm{C}$ and $400^{\circ} \mathrm{C}$. At the elevated temperature, acrolein was at the highest yield from both soybean oil and peanut oil, followed by formaldehyde, acetaldehyde and propionaldehyde. The heated pork lard produced 


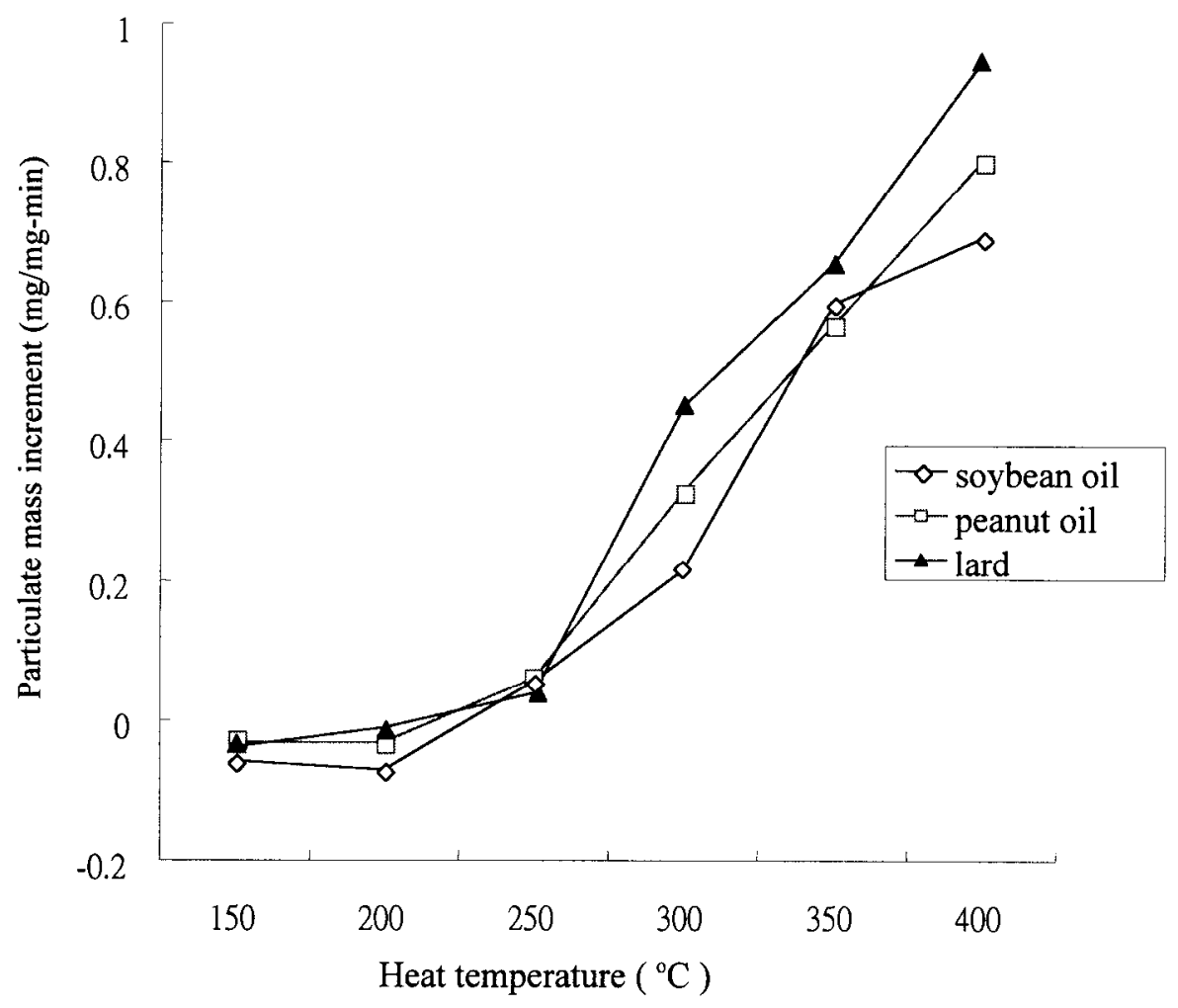

Figure 2. The oil-generated particulate mass at selected heating temperatures

an exceptionally high amount of formaldehyde $(10.9 \mathrm{ppm} / \mathrm{mg}-\mathrm{min})$ at $400^{\circ} \mathrm{C}$ followed by much lowered acetaldehyde $(1.04 \mathrm{ppm} / \mathrm{mg}$-min), acrolein $(0.66$ $\mathrm{ppm} / \mathrm{mg}$-min), and propionaldehyde $(0.33 \mathrm{ppm} / \mathrm{mg}-\mathrm{min})$. It is apparent that formaldehyde and acrolein were the major aldehyde species derived from heating cooking oils.

Figure 4 further demonstrates the relationship between the yield of aldehyde and the temperature applied to the oil. The lowest yield for all types of aldehyde occurred at the temperatures between $200^{\circ} \mathrm{C}$ and $300^{\circ} \mathrm{C}$. We considered this temperature as the break point prior for the re-initiation of aldehyde formation. Incidentally, the temperature ordinarily used for household cooking is $300^{\circ} \mathrm{C}$ and it may thus reduce the human exposure to these fumes. It is worthwhile to investigate whether women with lung cancer cook at higher temperatures leading to greater exposure to chemicals generated in the fume. 


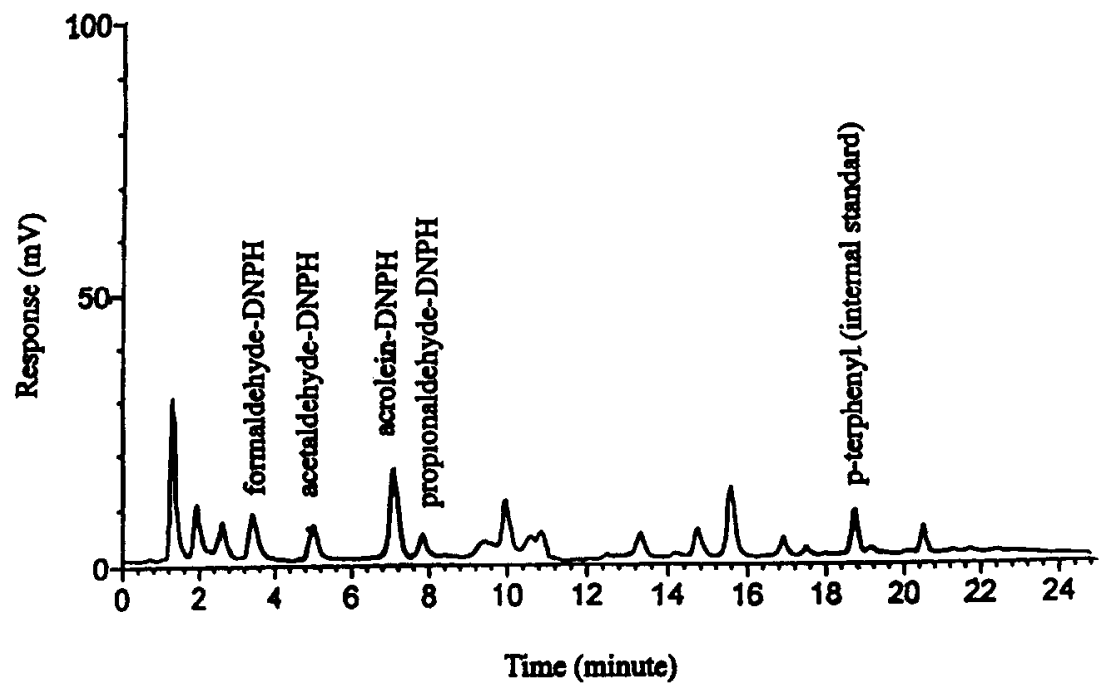

Figure 3. The HPLC chromatogram of the 2,4-dinitrophenyl hydrazine (2,4DNPH) derivatives of volatile aldehydes in cooking oil fumes

It has been reported that a significant amount of hexanal and aldehyde esters is detectable by heating samples of linoleic acid and its esters at a lower temperature $\left(180^{\circ} \mathrm{C}\right)$ due to autoxidation (Henderson et al, 1980). In contrast, relative large quantities of nonpolar components, especially the cyclic hydrocarbons, present in the fume generated from heating linoleic acid and its esters at $250{ }^{\circ} \mathrm{C}$ (Henderson et al, 1980). Similarly, the lower yields of aldehyde occurred at $250-300^{\circ} \mathrm{C}$ in this study might be due to the intramolecular cyclization and dimerization of unsaturated fatty acids. The higher yields of aldehyde at $350^{\circ} \mathrm{Cand}$ above may involve a large number of reactions including the thermolytic decomposition and oxygen attack on saturated fatty acids.

We have been unable to simplify mechanisms that can yet account for the quantitative differences observed at various temperatures. However, this study did demonstrate that oils are decomposed to a series of aldehydes that differ in species and amounts depending on the applied temperature. In conclusion, this study suggests that higher amount of acrolein can be recovered by heating oils at all temperature levels while exceptional high amount of formaldehyde is produced from heating pork lard at $400^{\circ} \mathrm{C}$. 
Table 1. Average yield of aliphatic aldehyde by applied temperature and heated cooking oil

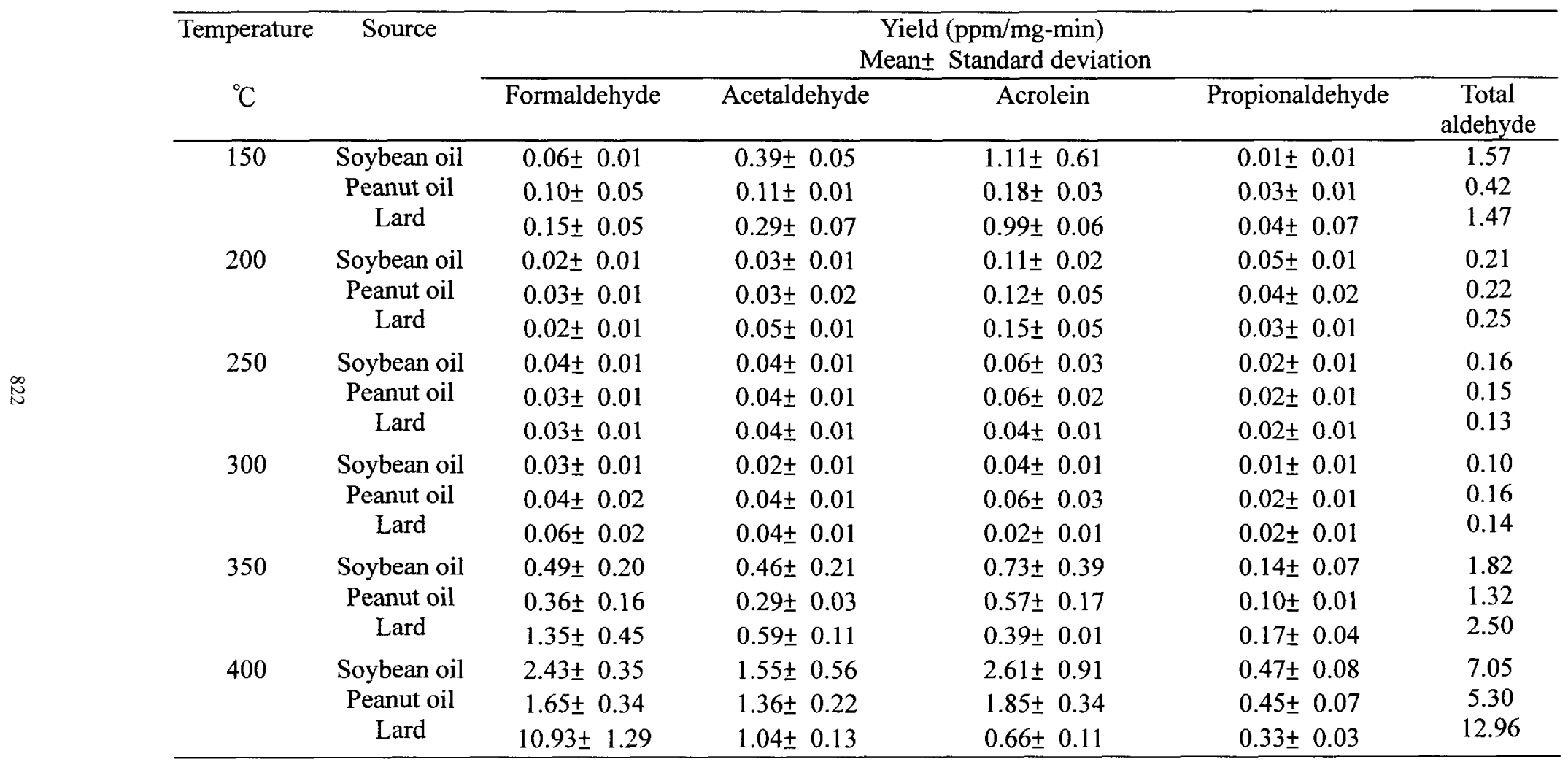

Number of samples in each set $=3$ 


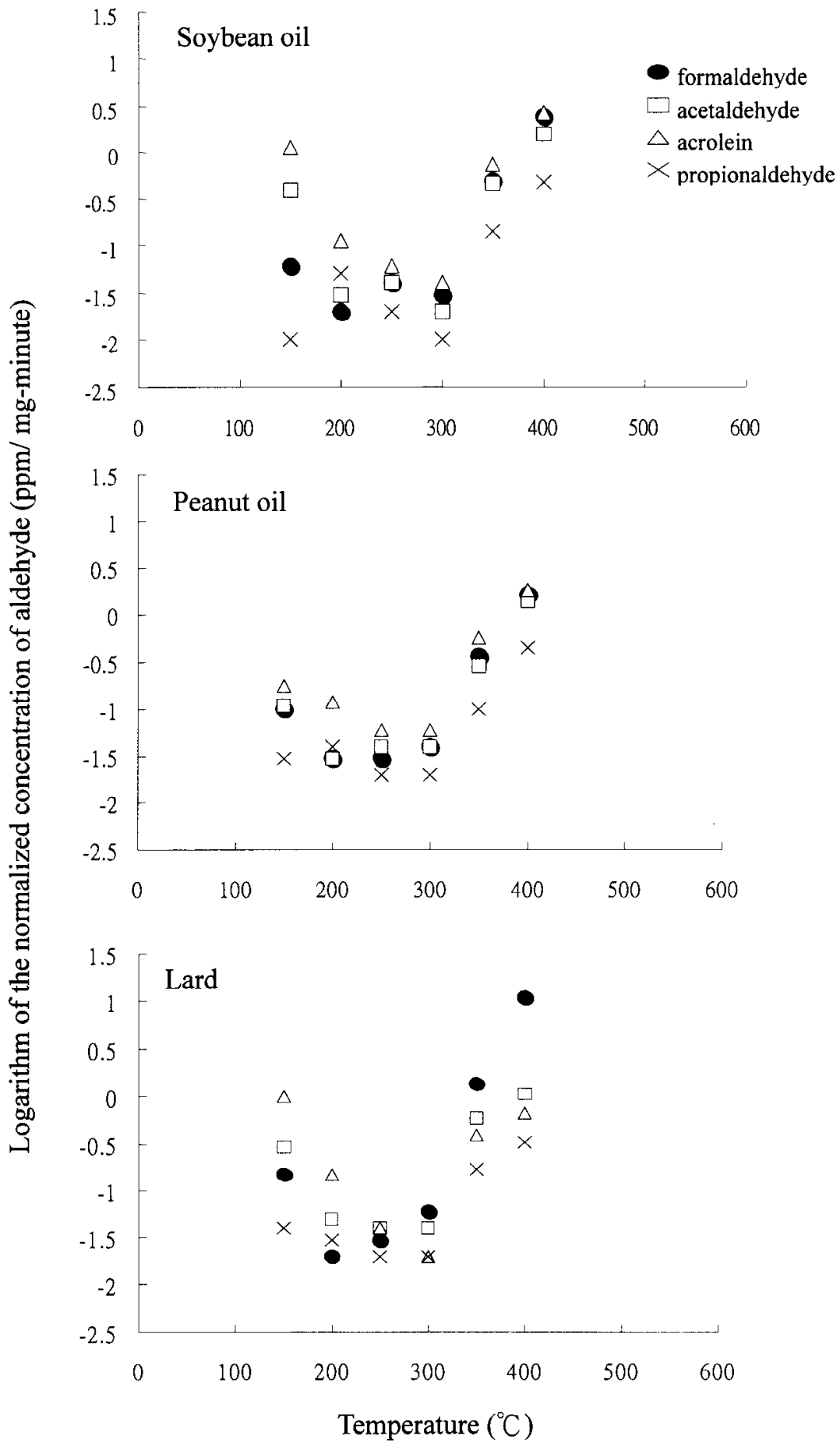

Figure 4. Relationship between the concentration of aldehyde and the temperature of heating oil 


\section{REFERENCES}

Berg I, Overvik E, Nord CE, Gustaffsson JA (1988) Mutagenic activity in smoke formed during broiling of lean pork at 200,250 and $300^{\circ} \mathrm{C}$ Mut Res 207: 199-204.

Berg I, Overvik E, Gustaffsson JA (1990) Effect of cooking time on mutagen formation in smoke, crust and pan residue from pan-broiled pork. Food Chem Toxicol 28:421-426.

Coggon D, Pannett B, Osmond CA (1984) Survey of cancer and occupation in young and middle age men. II. Non-respiratory cancer. British J Indust Med 43:381-386.

Coggon D, Wield G (1993) Mortality of army cooks. Scandinavian J Work Environ Health 19:85-88.

Felton JS, Knize MG, Shen NH, Andresen BD, Bjeldanes LF, and Hatch FT (1986) Identificationof the muagens in cooked beef. Environ Health Perspect 67: 17-24.

Henderson SK, Witchwoot A, Nawar WW (1980) The autoxidation of linoleates at elevated temperatures. J American Oil Chemists' Society 57: 409-413

Ko YC, Lee CH, Chen MJ, Huang CC, Chang UY, Lin HJ, Wang HZ, Chang PY (1997) Risk and protective factors for primary lung cancer among nonsmoking women in Taiwan. Int J Epidemiol 24: 24-31.

Law CH, Day NE (1976) Incidence rates of specific histological types of lung cancer in Singapore Chinese dialect groups and their aetiological significance. Int J Cancer 17: 304-09.

Li S, Pan D, Wang G (1994) Analysis of polycyclic aromatic hydrocarbons in cooking oil fumes. Archives Environ Health 49: 119-122.

Schoenberg JB, Sternhagen A, Mogielnicki AP (1984) Case-control study of bladder cancer in New Jersey. I. Occupational exposures in white males. J Natl Cancer Inst 72:973-981.

Shields PG, Xu GX, Blot WJ, Fraurneni JF, Trivers GE, Pellizzari ED, Qu YH, Gao YT, Harris CC (1995) Mutagens from heated Chinese and U. S. cooking oils. J Natl Cancer Inst 87:836-841. 